\title{
Auranofin, $\mathrm{Et}_{3} \mathrm{PAuCl}$, and $\mathrm{Et}_{3} \mathrm{PAul}$ Are Highly Cytotoxic on Colorectal Cancer Cells: A Chemical and Biological Study
}

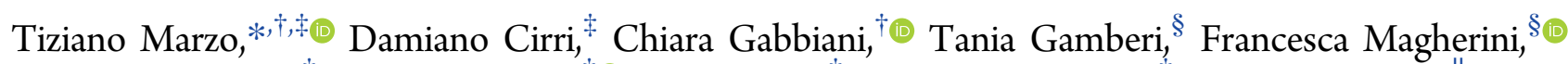
Alessandro Pratesi, ${ }^{\ddagger}$ Annalisa Guerri, ${ }^{\ddagger} \oplus$ Tarita Biver, ${ }^{\dagger}$ Francesca Binacchi, ${ }^{\dagger}$ Matteo Stefanini, Annarosa Arcangeli, ${ }^{\perp}$ and Luigi Messori ${ }^{*}$,

${ }^{\dagger}$ Department of Chemistry and Industrial Chemistry (DCCI), University of Pisa, Via Moruzzi, 13, 56124 Pisa, Italy

${ }^{\ddagger}$ Laboratory of Metals in Medicine (MetMed), Department of Chemistry “U. Schiff”, University of Florence, Via della Lastruccia 3, 50019 Sesto Fiorentino, Italy

${ }^{\S}$ Department of Biochemical, Experimental and Clinical Sciences “Mario Serio”, University of Florence, Viale GB Morgagni 50, 50134 Firenze, Italy

"DI.V.A.L Toscana S.R.L., Via Madonna del Piano, 6, 50019 Sesto Fiorentino, Italy

${ }^{\perp}$ Department of Experimental and Clinical Medicine, University of Florence, Viale GB Morgagni 50, 50134 Firenze, Italy

\section{Supporting Information}

\begin{abstract}
The solution behavior of auranofin, $\mathrm{Et}_{3} \mathrm{PAuCl}$ and $\mathrm{Et}_{3} \mathrm{PAuI}$, as well as their interactions with hen egg white lysozyme, single strand oligonucleotide, and ds-DNA were comparatively analyzed through NMR spectroscopy, ESI-MS, ethidium bromide displacement, DNA melting and viscometric tests. The cytotoxic effects toward representative colorectal cancer cell lines were found to be strong and similar in the three cases and a good correlation could be established between the cytotoxicity and the ability to inhibit thioredoxin reductase; remarkably, in vivo acute toxicity experiments for $\mathrm{Et}_{3} \mathrm{PAuI}$ confirmed that, similarly to auranofin, this drug is well tolerated in a murine model. Overall, a very similar profile emerges for $\mathrm{Et}_{3} \mathrm{PAuI}$ and $\mathrm{Et}_{3} \mathrm{PAuCl}$, which retain the potent cytotoxic effects of auranofin while showing some peculiar features. These results demonstrate that the presence of the thiosugar moiety is not mandatory for the pharmacological action, suggesting that the tuning of some relevant chemical properties such as lipophilicity could be exploited to improve bioavailability, with no loss of the pharmacological effects.

KEYWORDS: Auranofin, thioredoxin reductase, anticancer drugs, colorectal cancer, protein interaction, DNA interaction,

in vivo experiments
\end{abstract}

\begin{abstract}
A uranofin $[2,3,4,6$-tetra-o-acetyl-L-thio- $\beta$-D-glyco-pyranosato-S-(triethyl- phosphine)-gold(I)] (AF) is a clinically established oral chrysotherapeutic agent that is used for the treatment of some severe forms of rheumatoid arthritis. ${ }^{1}$ During the past few years, this drug has attracted renewed attention in the medicinal chemistry scientific community as a prospective anticancer and antimicrobial agent according to innovative drug repurposing strategies. ${ }^{2-4}$ In particular, AF has been, or still is, the object of clinical trials in the US as an anticancer agent. ${ }^{5,6}$ We thought that selective and limited chemical modifications of AF might lead to a modulation and hopefully an improvement of its pharmacological profile. To this regard, it is worth reminding that Frank Shaw, on the ground of similar arguments, prepared and characterized a few years ago seleno-auranofin, a derivative of auranofin where the thiosugar ligand is replaced by the corresponding selenosugar ligand, and obtained remarkable biological results. ${ }^{7}$ Accordingly, we decided to prepare a derivative of AF where the thiosugar ligand is replaced by one iodide ligand and to test this compound in comparison to AF and its commercially available chloride analogue. In principle, replacement of the thiosugar or chloride ligand with iodide should afford a compound of increased lipophilicity, thus enhancing drug bioavailability; at
\end{abstract}

the same time, substitution of such a large ligand as thioglucose tetraacetate with a monatomic ligand, i.e., iodide, should not affect substantially the drug's pharmacological profile as the thiosugar ligand is believed to act mainly as a carrier ligand and, also, as a good leaving group, while the $\mathrm{Et}_{3} \mathrm{PAu}^{+}$moiety is assumed to be the "true pharmacophore". In nice agreement with this view, previous studies showed that $\mathrm{Et}_{3} \mathrm{PAuCl}$ manifests biological properties similar though not identical to those of AF. ${ }^{8}$

$\mathrm{Et}_{3} \mathrm{PAuI}$ was synthesized starting from commercially available $\mathrm{Et}_{3} \mathrm{PAuCl}$. First, $\mathrm{Et}_{3} \mathrm{PAuCl}$ was treated with an excess of $\mathrm{KI}$ in ethanol at $25{ }^{\circ} \mathrm{C}$. After $3 \mathrm{~h}$, the mixture was dried and the resulting white solid kept at $-20{ }^{\circ} \mathrm{C}$ overnight. The product was then extracted with dichloromethane, and the recombined organic phase was washed with water and dried over $\mathrm{MgSO}_{4}$. After precipitation in pentane, white crystals of $\mathrm{Et}_{3} \mathrm{PAuI}$ were collected and dried.

Received: April 11, 2017

Accepted: September 6, 2017

Published: September 6, 2017 
$\mathrm{Et}_{3} \mathrm{PAuI}$ was characterized by elemental analysis, and NMR confirmed the purity of the synthesized compound (see S2 in Supporting Information). A $\log P$ value of 4.6 was found for $\mathrm{Et}_{3} \mathrm{PAuI}$ making this complex by far the most lipophilic of the series. Indeed, $\log P$ values of 1.7 and 1.6 were, respectively measured for $\mathrm{Et}_{3} \mathrm{PAuCl}$ and $\mathrm{AF}$ ( $\mathrm{S} 19$ in Supporting Information for details on the method for $\log P$ determination).

Single crystals of $\mathrm{Et}_{3} \mathrm{PAuI}$, suitable for $\mathrm{X}$-ray diffraction studies, were obtained by adding pentane to a concentrated solution of the compound in dichloromethane. The solution was kept at $-20{ }^{\circ} \mathrm{C}$ for 1 week. After this time needle-shaped crystals were formed (Figure 1 and S22 in Supporting Information for crystallographic data).

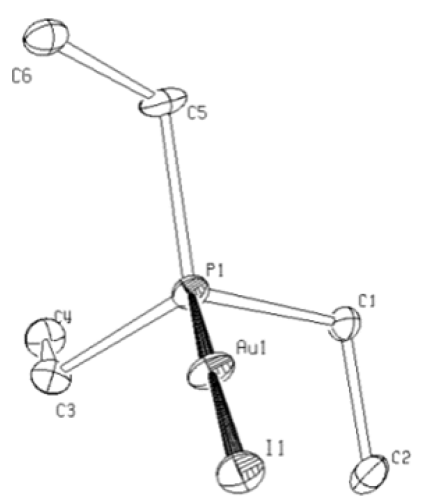

Figure 1. X-ray structure of complex $\mathrm{Et}_{3} \mathrm{PAuI}$. The gold(I) ion is linearly coordinated to the $\mathrm{I}(1)$ and $\mathrm{P}(1)$ atoms, with distance of $2.5898(1)$ and $2.268(2) \AA$, respectively. The angle $\mathrm{P}(1)-\mathrm{Au}(1)-\mathrm{I}(1)$ is $178.89(6)^{\circ}$.

The crystal structure was solved to $0.73 \AA$ resolution. The geometry as well as the distances reported in Figure 1 are in good agreement with bond lengths and angles found in similar compounds retrieved from the CSD (v. 5.37 February 2016). It is worth reminding that the $\mathrm{Au}-\mathrm{I}$ bond length generally increases as the hindrance of the substituents of the $\mathrm{P}$ atom decreases $\left(\mathrm{P}-t-\mathrm{Bu}_{3}, \mathrm{P}-\mathrm{i}-\mathrm{Pr}_{3}, \mathrm{P}-\mathrm{Et}_{3}\right.$ of $2.56,2.58$, and $2.59 \AA$, respectively). ${ }^{9}$

Afterward, $\mathrm{Et}_{3} \mathrm{PAuI}$ was investigated for its chemical and biological properties in solution in comparison to $\mathrm{AF}$ and $\mathrm{Et}_{3} \mathrm{PAuCl}$. The solution behavior of the three species was mainly assessed by ${ }^{31} \mathrm{P}$ NMR spectroscopy. The three compounds were solubilized in trizma base $/ \mathrm{CH}_{3} \mathrm{COOH}, 6$ $\mathrm{mM}$, in the presence of $250 \mu \mathrm{L}$ of $\mathrm{H}_{2} \mathrm{O} ; 650 \mu \mathrm{L}$ of $\mathrm{CH}_{3} \mathrm{OH}$; $200 \mu \mathrm{L}$ of $\mathrm{CD}_{3} \mathrm{OD}, \mathrm{pH} 7$, and analyzed at increasing time intervals. Notably, all three compounds manifest a high stability for several hours with no evidence of ligand detachment. Indeed, changes in the ${ }^{31} \mathrm{P}$ NMR spectra could only be detected after very long incubation times. For $\mathrm{Et}_{3} \mathrm{PAuI}$, no changes were seen after $72 \mathrm{~h}$; however, after 1 week of incubation, beside the signal falling at $41 \mathrm{ppm}$ (assigned to the phosphorus in the neutral complex), a new signal of low intensity appeared at 47 $\mathrm{ppm}$. This new signal is tentatively attributed to phosphorus in the cationic monocharged complex $\mathrm{Au}\left(\mathrm{PEt}_{3}\right)_{2}{ }^{+}$, which is likely formed through rearrangement, according to the equilibrium (Scheme 1). ${ }^{10,11}$

Scheme 1. Ligand Scrambling Reaction of $\mathrm{Et}_{3} \mathrm{PAuI}$

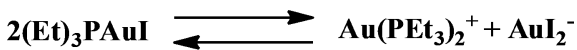

The signal increases in intensity until day 14; no further changes in intensity were detected afterward, even after 35 days, indicating that the reaction has reached its equilibrium (Figure 2 and S4-S8 in Supporting Information for details and spectra).

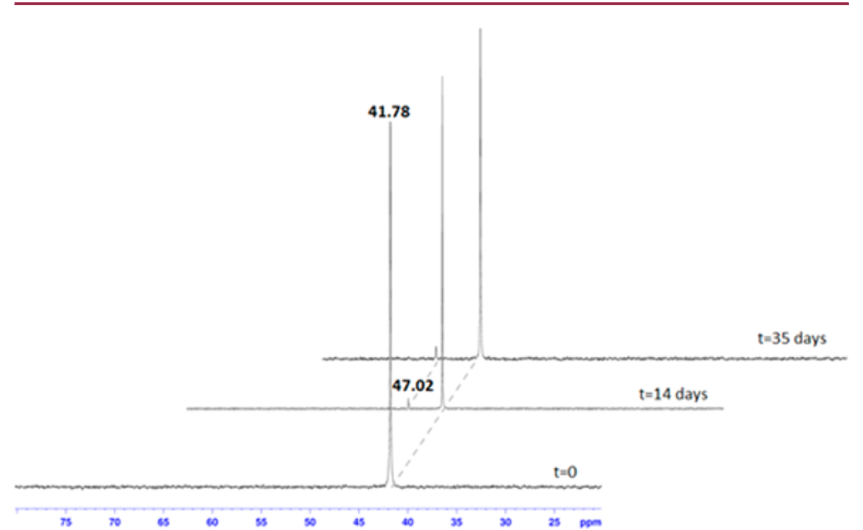

Figure 2. ${ }^{31} \mathrm{P}$ NMR spectra (trizma base $/ \mathrm{CH}_{3} \mathrm{COOH} 6 \mathrm{mM}$ in a mixture of $250 \mu \mathrm{L}$ of $\mathrm{H}_{2} \mathrm{O} ; 650 \mu \mathrm{L}$ of $\mathrm{CH}_{3} \mathrm{OH} ; 200 \mu \mathrm{L}$ of $\mathrm{CD}_{3} \mathrm{OD}$, pH 7) of $\mathrm{Et}_{3} \mathrm{PAuI}$ recorded at different time intervals.

Formation of $\mathrm{Au}\left(\mathrm{PEt}_{3}\right)_{2}{ }^{+}$was independently confirmed treating $\mathrm{Et}_{3} \mathrm{PAuI}$ with $\mathrm{AgNO}_{3}$, under the same solution conditions, and then analyzing the reaction products by ${ }^{31} \mathrm{P}$ NMR and HR ESI-MS at different times intervals (S9-S10 in Supporting Information). When recording a ${ }^{31} \mathrm{P}$ NMR spectrum immediately after treatment with $\mathrm{AgNO}_{3}$ we found only a signal falling at $30.43 \mathrm{ppm}$ assignable to $\mathrm{Et}_{3} \mathrm{PAu}\left(\mathrm{H}_{2} \mathrm{O}\right)^{+}$ species. ${ }^{12}$ After five days, a new ${ }^{31} \mathrm{P}$ NMR spectrum was recorded on the same sample: beside the signal at $30.43 \mathrm{ppm}$, a new one at $47.85 \mathrm{ppm}$ was detected and assigned to the monopositive cation complex $\mathrm{Au}\left(\mathrm{PEt}_{3}\right)_{2}{ }^{+}$. Further confirmation came from ESI-MS analysis. In the spectrum recorded five days after treatment with $\mathrm{AgNO}_{3}$, we found three main signals at 315.1, 333.1, and 433.15 $\mathrm{Da}$ assignable, respectively, to the three species $\mathrm{Et}_{3} \mathrm{PAu}^{+}, \mathrm{Et}_{3} \mathrm{PAu}\left(\mathrm{H}_{2} \mathrm{O}\right)^{+}$, and $\mathrm{Au}\left(\mathrm{PEt}_{3}\right)_{2}{ }^{+}$. Attributions were validated through theoretical simulation of the various species. Finally, to obtain an additional proof that the ${ }^{31} \mathrm{P}$ NMR signal at $47 \mathrm{ppm}$ corresponds to formation of $\mathrm{Au}\left(\mathrm{PEt}_{3}\right)_{2}{ }^{+}$species, we synthesized this complex by treatment of $\mathrm{Et}_{3} \mathrm{PAuCl}$ with an excess of triethylphosphine. The ${ }^{31} \mathrm{P}$ analysis of the resulting product confirmed the obtainment of the desired compound and, accordingly, our assignment (see S17-S19 in the Supporting Information for further details on the synthesis and NMR spectrum). A quite different situation was found for the ${ }^{31} \mathrm{P}$ NMR spectra of $\mathrm{AF}$ and $\mathrm{Et}_{3} \mathrm{PAuCl}$, for which no significant changes were detected even after 35 days of incubation. However, all three compounds show a large stability in solution even when incubated in the presence of $\mathrm{NaCl} 0.9 \%$ as well as in $10 \mathrm{mM}$ PBS buffer, rendering them well suitable for pharmacological testing and application (S11 in Supporting Information).

Next, the antiproliferative properties of the three complexes were measured in vitro against HCT8, HCT116, HT29, and Caco2, four representative cell lines of colorectal cancer (CRC) as well as on HDF (human fibroblast, adult) and HEK293 (human embryonic kidney) cell lines. As displayed in Table 1, all three drugs produce potent cytotoxic effects on the selected CRC cell lines with $\mathrm{IC}_{50}$ values always falling in the 100-700 $\mathrm{nM}$ range. $\mathrm{Et}_{3} \mathrm{PAuI}$ is slightly less cytotoxic than the other two 
Table 1. IC $_{50}$ Values (nM) Determined for $\mathrm{Et}_{3} \mathrm{PAuI}, \mathrm{AF}$, and $\mathrm{Et}_{3} \mathrm{AuPCl}$ ( $24 \mathrm{~h}$ Incubation $)^{a}$

$\begin{array}{lccccc}\text { complex } & \text { HCT8 } & \text { HCT116 } & \text { HT29 } & \text { Caco2 } & \text { HDK } \\ \mathrm{AF} & 132 \pm 16 & 180 \pm 17 & 359 \pm 35 & 465 \pm 53 & >5000 \\ \mathrm{Et}_{3} \mathrm{PAuCl} & 105 \pm 11 & 154 \pm 22 & 122 \pm 15 & 560 \pm 93 & >5000 \\ \mathrm{Et}_{3} \mathrm{PAuI} & 260 \pm 28 & 290 \pm 36 & 318 \pm 90 & 706 \pm 232\end{array}$

${ }^{a}$ Results are reported as average value for three independent experiments \pm SD.

gold complexes. In any case, the presence of the thiosugar ligand is not an essential requirement for the cytotoxic action, ${ }^{13}$ in line with expectations. In addition, upon considering the close similarity in the measured $\mathrm{IC}_{50}$ values, substantial differences in the cellular uptake are unlikely. Remarkably, measuring the cytotoxic effects on two normal cell lines, HDF human fibroblast cells (adult) and HEK293 human embryonic kidney (Table 1, S24 in Supporting Information), no cytotoxic effect was found for the three study complexes in the range 0$5000 \mathrm{nM}$.

Next, in view of the fact that thioredoxin reductase (TrxR) is a likely important target for $\mathrm{AF}^{14}$ we have comparatively quantified the inhibitory potency of the three drugs toward this enzyme. Results are summarized in Table 2.

Table 2. Thioredoxin Reductase Activity Assay ${ }^{a}$

$\begin{array}{lc}\text { complex } & \mathrm{IC}_{50}(\mathrm{nM}) \\ \mathrm{AF} & 105 \pm 17.3 \\ \mathrm{Et}_{3} \mathrm{AuPCl} & 51.3 \pm 8.5 \\ \mathrm{Et}_{3} \mathrm{PAuI} & 193 \pm 22.2\end{array}$

${ }^{a} \mathrm{IC}_{50}$ values $(\mathrm{nM})$ were determined treating $2 \mathrm{U} / \mathrm{L}$ of $\operatorname{TrxR}$ with aliquots of $\mathrm{AF}, \mathrm{Et}_{3} \mathrm{AuPCl}$, and $\mathrm{Et}_{3} \mathrm{PAuI}$ (from $1 \mu \mathrm{M}$ to $1 \mathrm{nM}$ ). Results are reported as average value for three independent experiments \pm SD.

It is interesting to note that the obtained $\mathrm{IC}_{50}$ values for TrxR inhibition are in line with those obtained for the cytotoxic effects on CRC cell lines (Table 1). This might imply that the observed cytotoxic effects are somehow related to the ability of these gold complexes to bind and inhibit TrxR. Moreover, results highlight and confirm that $\mathrm{Et}_{3} \mathrm{PAuCl}$ is not only the most potent cytotoxic agent but also the most potent TrxR inhibitory agent of the series, though $\mathrm{IC}_{50}$ values for $\mathrm{AF}$ and $\mathrm{Et}_{3} \mathrm{PAuI}$ still fall in the nanomolar range (see S25 in Supporting Information for experimental details on TrxR inhibition assay).

To better characterize the mechanistic aspects of the interactions occurring between these gold compounds and probable biological targets, we have studied their reactions toward the model protein lysozyme (HEWL) and the GG rich oligonucleotide CTACGGTTTCAC (ODN) through ESI-MS analysis. Notably, upon replacing the thiosugar ligand with a halide ligand, e.g., chloride or iodide, we observed a net change in metallodrug reactivity toward HEWL. Indeed, AF interacts appreciably with HEWL, apparently through formation of noncovalent adducts, where the neutral intact drug is bound to the protein (Figure 3); in contrast, both iodide and chloride derivatives do not react with HEWL even after long incubation times (see S19-S21 in Supporting Information for ESI-MS spectra). This different behavior might be ascribed to a crucial role of the thiosugar ligand in forming noncovalent protein adducts.

Conversely, replacement of the thiosugar ligand with halide ligands greatly enhances reactivity toward oligonucleotide. In fact, both $\mathrm{Et}_{3} \mathrm{PAuI}$ and $\mathrm{Et}_{3} \mathrm{PAuCl}$ coordinate this target through selective release of halide ligands roughly in the same manner

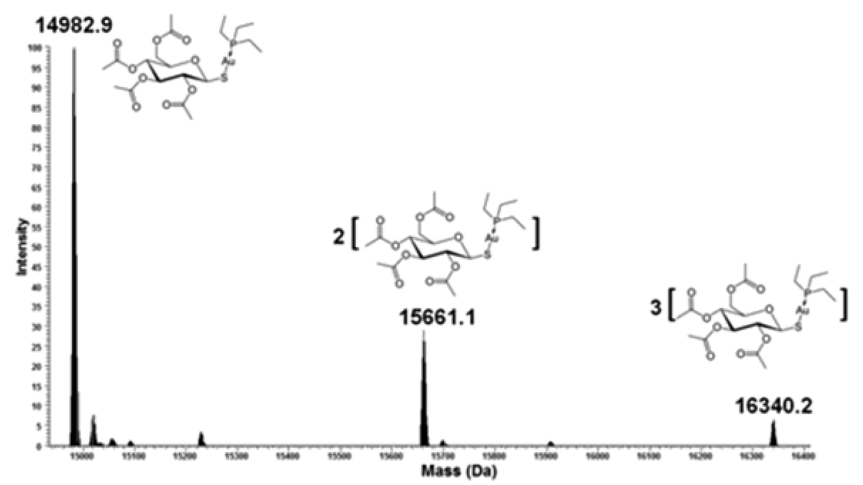

Figure 3. Close-up of deconvoluted ESI-MS spectrum (positive mode) of AF incubated $72 \mathrm{~h}\left(37^{\circ} \mathrm{C}\right)$ with HEWL $\left(10^{-4} \mathrm{M}\right)$ in ammonium acetate buffer, $20 \mathrm{mM}, \mathrm{pH} 6.8$; metal to protein ratio (3:1), $3 \%$ DMSO.

(Figure 4); also, similar amounts of the corresponding adducts are formed.

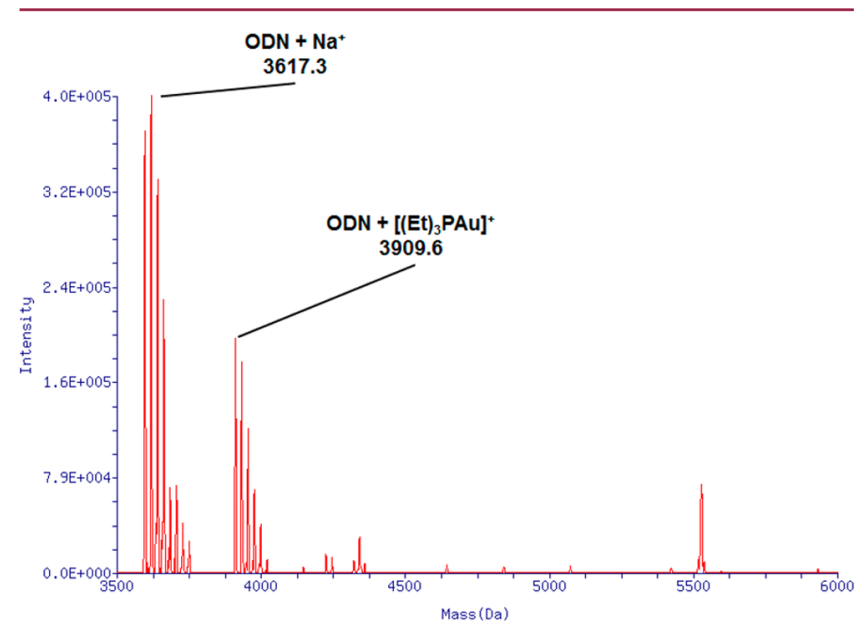

Figure 4. Deconvoluted ESI-MS spectrum (negative mode) of $\mathrm{Et}_{3} \mathrm{PAuI}$ incubated $72 \mathrm{~h}\left(37^{\circ} \mathrm{C}\right)$ with ODN $\left(10^{-4} \mathrm{M}\right)$ in $\mathrm{LC}-\mathrm{H}_{2} \mathrm{O}$ metal to protein ratio (3:1), $3 \%$ DMSO.

In contrast, when performing the same experiment with $\mathrm{AF}$, no adduct formation with ODN was observed; this finding is relevant even considering that $\mathrm{AF}$ does not react with double helix DNA as previously reported by Mirabelli and coworkers, ${ }^{15}$ and the same kind of reactivity is preserved toward the single strand ODN model. Notably, when AF is incubated with ODN, it only produces a main peak at $923 \mathrm{~m} / z$ assignable to the species in Figure 5, as previously reported (see S22 in Supporting Information for spectrum). ${ }^{16}$

Encouraged by the results obtained with ss-ODN, the possible interactions of $\mathrm{AF}$ analogues with double-stranded DNA (more precisely, calf thymus DNA) were comparatively investigated by the ethidium bromide $(\mathrm{EtBr})$ assay. DNA is first saturated with the $\mathrm{EtBr}$ probe producing a fluorescent 


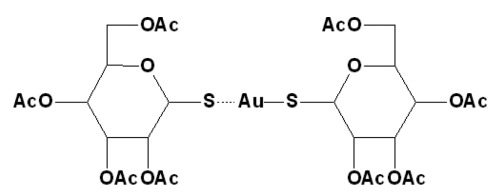

Figure 5. Structure of the main species produced by AF: structure corresponds to the peak at $923 \mathrm{~m} / z$.

intercalation complex (while free dye is non-emissive). Then, increasing amounts of the drug are added: a fluorescence decrease indicates progressive $\mathrm{EtBr}$ displacement and buildup of drug-DNA interactions. ${ }^{17,18}$ We found, indeed, that both $\mathrm{Et}_{3} \mathrm{PAuCl}$ and $\mathrm{Et}_{3} \mathrm{PAuI}$ produce a net fluorescence decrease, while AF does not (see S25 Supporting Information). The emission decrease is limited, in agreement with the nonintercalative nature of the binding, yet significant. Melting temperatures of drug-DNA mixtures do not vary appreciably from those of DNA alone (changes in the melting temperatures are in the range $\pm 2{ }^{\circ} \mathrm{C}$ in agreement with monodentate coordination of the drug to DNA strands; see S26 in Supporting Information). Conversely, viscosity undergoes significant changes for $\mathrm{Et}_{3} \mathrm{PAuCl} / \mathrm{DNA}$ and $\mathrm{Et}_{3} \mathrm{PAuI} / \mathrm{DNA}$ systems compared to the control (Figure 6, details in

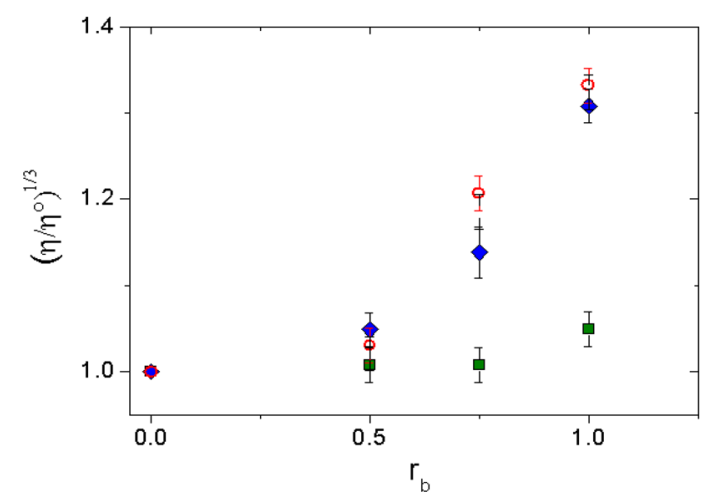

Figure 6. Viscometric plots $\left(25^{\circ} \mathrm{C}\right)$ for $\mathrm{Et}_{3} \mathrm{PAuI} / \mathrm{DNA}$ (open circles), $\mathrm{Et}_{3} \mathrm{PAuCl} / \mathrm{DNA}$ (diamonds), and $\mathrm{AF} / \mathrm{DNA}$ (squares) systems. $r_{\mathrm{b}}=$ [drug]/[DNA] (base pairs), $[\mathrm{DNA}]=2.5 \times 10^{-5} \mathrm{M}, \eta / \eta^{\circ}=(t-$ $\left.t_{\text {solv }}\right) /\left(t_{\mathrm{DNA}}-t_{\text {solv }}\right)$ where $t, t_{\text {solv }}$, and $t_{\mathrm{DNA}}$ are the efflux times in the capillary viscometer of the mixture, of the buffer $(\mathrm{NaCl} 0.1 \mathrm{M}, \mathrm{Na}-$ cacodylate $0.01 \mathrm{M}, \mathrm{pH} 7$ ) and of DNA alone, respectively.

Supporting Information S27), suggesting that the bound drugs significantly affect the helix flexibility. This strong effect, which is not observed upon $\mathrm{AF}$ addition, confirms that the auranofin analogues manifest a reactivity significantly different from $\mathrm{AF}$ and are able to bind ds-DNA.

Finally, in vivo acute toxicity experiments for $\mathrm{Et}_{3} \mathrm{PAuI}$ were carried out to assess whether this complex is tolerated in murine model (see S27 in Supporting Information for details on the protocol). Three doses were tested (i.e., 10, 15, and 30 $\mathrm{mg} / \mathrm{kg}$ ) on three groups of animals (each group consisted in three mice). The weight and the behavior of mice was monitored every day during all the treatment, and there was no evidence for weight loss; also, no evidence for loss of appetite and mobility reduction were found. Remarkably, neither microscopic or macroscopic alteration was found in liver, kidneys, and spleen. Obtained results highlight that the treatment has been well tolerated in murine models and that the toxicity profile of this drug is low and similar to that reported for $\mathrm{AF}^{19}$
In conclusion, we have prepared and characterized here a novel $\mathrm{Au}(\mathrm{I})$ complex that is a close analogue of AF featuring the simple replacement of the thiosugar ligand with iodide. Similarly to $\mathrm{AF}$ and $\mathrm{Et}_{3} \mathrm{PAuCl}, \mathrm{Et}_{3} \mathrm{PAuI}$ shows a high stability under physiological-like conditions while manifesting a far greater lipophilic character. Interestingly, $\mathrm{Et}_{3} \mathrm{PAuI}$ retains the large cytotoxic effects of $\mathrm{AF}$ and $\mathrm{Et}_{3} \mathrm{PAuCl}$ toward four representative $\mathrm{CRC}$ cell lines, with the measured $\mathrm{IC}_{50}$ values still falling in the nanomolar range and no cytotoxic effect on human fibroblast cell line and human embryonic kidney cells. This implies that the presence of the thiosugar moiety is not mandatory for the pharmacological action. The TrxR assay reveals that both $\mathrm{Et}_{3} \mathrm{PAuCl}$ and $\mathrm{Et}_{3} \mathrm{PAuI}$ retain the potent inhibitory action of AF (nanomolar range), being consistent with their observed cytotoxic effect, with $\mathrm{AF}$ and $\mathrm{Et}_{3} \mathrm{AuPCl}$ slightly more active than $\mathrm{Et}_{3} \mathrm{PAuI}$. However, mechanistic differences were highlighted among the three investigated gold complexes with both $\mathrm{Et}_{3} \mathrm{PAuI}$ and $\mathrm{Et}_{3} \mathrm{PAuCl}$ being unreactive toward HEWL but capable of binding to a standard ss-ODN sequence and to ds-DNA. At variance, AF can bind noncovalently to the model protein but does not form coordinative adducts to ssODN and does not bind calf thymus DNA.

In our opinion, the present results are of particular interest for the following reasons:

(i) Substitution of the thiosugar with iodide and chloride "tunes" the reactivity of these compounds for model biological targets rendering them more selective toward oligo- and polynucleotides. At variance from AF, where the tetraacetate-thiosugar moiety allows formation of noncovalent adducts with lysozyme, this kind of binding is not observed in the cases of $\mathrm{Et}_{3} \mathrm{PAuI}$ and $\mathrm{Et}_{3} \mathrm{PAuCl}$. Yet, it is worth reminding that even $\mathrm{AF}$ is not able to form coordinative bonds to HEWL. Binding of gold(I) metal center to histidine and methionine residues of lysozyme was previously described mainly as a naked cation; ${ }^{20}$ but this does not occur for AF and its analogues due to the very high stability of the ligands and their steric hindrance. Furthermore, these differences in reactivity toward the model protein HEWL do not correlate with their strong inhibitory power toward TrxR, being this latter aspect most probably related with the very high affinity of gold for the selenium donor and thus for the selenocysteine residue.

(ii) The enhanced reactivity of the gold(I) center toward the model oligonucleotide and the double helix DNA upon replacement of the thiosugar ligand with halide ligands may be the result of the greater lability of the goldhalide bond compared to the gold-sulfur bond; ${ }^{13}$ the guanine residue of nucleic acids that is highly accessible may "assist" halide detachment. Yet, this augmented reactivity for DNA molecules does not lead to enhanced cytotoxic effects. This might support the view that AF and also its halido analogues exert their strong cytotoxic effects mainly through DNA-independent mechanisms. ${ }^{21}$

(iii) The in vivo acute toxicity test carried out in a murine model, for the treatment with the complex $\mathrm{Et}_{3}$ PAuI, does not show any side effects, and the treatment has been well tolerated. This evidence is of great significance and warrants further preclinical assessments.

Overall, these findings are of significant interest if one considers that even small differences in biomolecular reactivity 
may result in large differences in the respective pharmacodynamic and pharmacokinetic profiles. In addition, the far greater lipophilic character of $\mathrm{Et}_{3} \mathrm{PAuI}$ might lead to an enhanced bioavailability of the latter drug.

\section{ASSOCIATED CONTENT}

\section{S Supporting Information}

The Supporting Information is available free of charge on the ACS Publications website at DOI: 10.1021/acsmedchemlett.7b00162.

\section{CIF report (PDF)}

Synthesis and characterization of $\mathrm{Et}_{3} \mathrm{PAuI}$; solution behavior; analysis after treatment with $\mathrm{AgNO}_{3}$; stability in physiological like conditions; synthesis and characterization of $\mathrm{Au}\left(\mathrm{Et}_{3} \mathrm{P}\right)_{2}{ }^{+} \mathrm{Cl}^{-}$; $\log P$ determination; ESI-MS experiments; X-ray diffraction; cellular studies (WST-1); enzyme activity inhibition in vitro; ethidium bromide $(\mathrm{EtBr})$ assay; melting tests; viscosimetric measurements; in vivo experiment protocol (PDF)

\section{AUTHOR INFORMATION}

\section{Corresponding Authors}

*E-mail: tiziano.marzo@dcci.unipi.it.

*E-mail: luigi.messori@unifi.it.

\section{ORCID}

Tiziano Marzo: 0000-0002-2567-3637

Chiara Gabbiani: 0000-0002-8468-4838

Francesca Magherini: 0000-0001-8388-0952

Annalisa Guerri: 0000-0001-6265-7874

\section{Author Contributions}

The manuscript was written through contributions of all authors. All authors have given approval to the final version of the manuscript.

\section{Notes}

The authors declare no competing financial interest.

\section{ACKNOWLEDGMENTS}

We gratefully acknowledge Beneficentia Stiftung, ITT (Istituto Toscano Tumori), Ente Cassa Risparmio Firenze (ECR), AIRC (IG-16049), COST Action CM1105, and University of Pisa (PRA_2017_25, to C.G. and T.M.) for financial support, and CISM (University of Florence) for ESIMS spectra. T.M. thanks AIRC-FIRC (Fondazione Italiana per la Ricerca sul Cancro, 3years Fellowship for Italy, Project Code: 18044). CIRCMSB is also acknowledged.

\section{DEDICATION}

This paper is dedicated to the memory of C. Frank Shaw III.

\section{REFERENCES}

(1) Shaw, C. F., III Gold-Based Therapeutic Agents. Chem. Rev. 1999, 99, 2589-2600.

(2) Cassetta, M. I.; Marzo, T.; Fallani, S.; Novelli, A.; Messori, L. Drug repositioning: auranofin as a prospective antimicrobial agent for the treatment of severe staphylococcal infections. BioMetals 2014, 27, 787-791.

(3) Fiskus, W.; Saba, N.; Shen, M.; Ghias, M.; Liu, J.; Gupta, S. D.; Chauhan, L.; Rao, R.; Gunewardena, S.; Schorno, K.; Austin, C. P.; Maddocks, K.; Byrd, J.; Melnick, A.; Huang, P.; Wiestner, A.; Bhalla, K. N. Auranofin Induces Lethal Oxidative and Endoplasmic Reticulum Stress and Exerts Potent Preclinical Activity against Chronic Lymphocytic Leukemia. Cancer Res. 2014, 74, 2520-2532.
(4) Madeira, J. M.; Gibson, D. L.; Kean, W. F.; Klegeris, A. The biological activity of auranofin: implications for novel treatment of diseases. Inflammopharmacology 2012, 20, 297-306.

(5) Phase I and II Study of Auranofin in Chronic Lymphocytic Leukemia (CLL). https://clinicaltrials.gov/ct2/show/NCT01419691.

(6) Auranofin in Treating Patients With Recurrent Epithelial Ovarian, Primary Peritoneal, or Fallopian Tube Cancer. https:// clinicaltrials.gov/ct2/show/NCT01747798.

(7) Hill, D. T.; Isab, A. A.; Griswold, D. E.; DiMartino, M. J.; Matz, E. D.; Figueroa, A. L.; Wawro, J. E.; DeBrosse, C.; Reiff, W. M.; Elder, R. C.; Jones, B.; Webb, J. W.; Shaw, C. F., III Seleno-Auranofin (Et ${ }_{3} \mathrm{PAuSe}$-tagl): Synthesis, Spectroscopic (EXAFS,197Au Mössbauer, ${ }^{31} \mathrm{P},{ }^{1} \mathrm{H},{ }^{13} \mathrm{C}$, and ${ }^{77} \mathrm{Se}$ NMR, ESI-MS) Characterization, Biological Activity, and Rapid Serum Albumin-Induced Triethylphosphine Oxide Generation. Inorg. Chem. 2010, 49, 7663-7675.

(8) Sutton, B. M.; McGusty, E.; Walz, D. T.; DiMartino, M. J. Oral gold. Antiarthritic properties of alkylphosphinegold coordination complexes. J. Med. Chem. 1972, 15, 1095-1098.

(9) Allen, F. H. The Cambridge Structural Database: a quarter of a million crystal structures and rising. Acta Crystallogr., Sect. B: Struct. Sci. 2002, B58, 380-388.

(10) Ahmad, S.; Isab, A. A. Synthesis of cyano(ergothionine)gold(I) complex and its disproportionation in solution. Inorg. Chem. Commun. 2001, 4, 362-364.

(11) Ahmad, S.; Isab, A. A. ${ }^{13} \mathrm{C},{ }^{31} \mathrm{P}$ and ${ }^{15} \mathrm{~N}$ NMR studies of the ligand exchange reactions of auranofin and chloro(triethylphosphine)gold(I) with thiourea. J. Inorg. Biochem. 2002, 88, 44-52.

(12) El-Etri, M. M.; Scovell, W. M. Synthesis and spectroscopic characterization of (triethylphosphine)gold(I) complexes $\mathrm{AuX}\left(\mathrm{PEt}_{3}\right)$ $(\mathrm{X}=\mathrm{Cl}, \mathrm{Br}, \mathrm{CN}, \mathrm{SCN}),\left[\mathrm{AuL}\left(\mathrm{PEt}_{3}\right)^{+}\right]\left(\mathrm{L}=\mathrm{SMe}_{2}, \mathrm{SC}\left(\mathrm{NH}_{2}\right)_{2}, \mathrm{H}_{2} \mathrm{O}\right)$, and (.mu.-S) $\left[\mathrm{Au}\left(\mathrm{PEt}_{3}\right)\right]_{2}$. Inorg. Chem. 1990, 29, 480-484.

(13) Mirabell, C. K.; Johnson, R. K.; Hill, D. T.; Faucette, L. F.; Girard, G. R.; Kuo, G. Y.; Sung, C. M.; Crooke, S. T. Correlation of the in vitro cytotoxic and in vivo antitumor activities of gold(I) coordination complexes. J. Med. Chem. 1986, 29, 218-223.

(14) Cox, A. G.; Brown, K. K.; Arner, E. S.; Hampton, M. B. The thioredoxin reductase inhibitor auranofin triggers apoptosis through a $\mathrm{Bax} / \mathrm{Bak}$-dependent process that involves peroxiredoxin 3 oxidation. Biochem. Pharmacol. 2008, 76, 1097-109.

(15) Mirabelli, C. K.; Sung, C. M.; Zimmerman, J. P.; Hill, D. T.; Mong, S.; Crooke, S. T. Interactions of gold coordination complexes with DNA. Biochem. Pharmacol. 1986, 35, 1427-1433.

(16) Albert, A.; Brauckmann, C.; Blaske, F.; Sperling, M.; Engelhard, C.; Karst, U. Speciation analysis of the antirheumatic agent Auranofin and its thiol adducts by LC/ESI-MS and LC/ICP-MS. J. Anal. At. Spectrom. 2012, 27, 975-981.

(17) Biver, T.; Secco, F.; Tinè, M. R.; Venturini, M.; Bencini, A.; Bianchi, A.; Giorgi, C. Intercalation of $\mathrm{Zn}$ (II) and $\mathrm{Cu}$ (II) complexes of the cyclic polyamine Neotrien into DNA: equilibria and kinetics. J. Inorg. Biochem. 2004, 98, 1531-1538.

(18) Marzo, T.; Pillozzi, S.; Hrabina, O.; Kasparkova, J.; Brabec, V.; Arcangeli, A.; Bartoli, G.; Severi, M.; Lunghi, A.; Totti, F.; Gabbiani, C.; Quiroga, A. G.; Messori, L. cis-Pt $\mathrm{I}_{2}\left(\mathrm{NH}_{3}\right)_{2}$ : a reappraisal. Dalton Trans. 2015, 44, 14896-14905.

(19) Auranofin SDS (Safety Data sheet); Cayman Chemical, revision 10/15/2014, according to regulation (EC) No. 1907/2006 as amended by (EC) No. 1272/2008.

(20) Ferraro, G.; Massai, L.; Messori, L.; Cinellu, M. A.; Merlino, A. Structural evidences for a secondary gold binding site in the hydrophobic box of lysozyme. BioMetals 2015, 28, 745-754.

(21) Rigobello, M. P.; Scutari, G.; Boscolo, R.; Bindoli, A. Induction of mitochondrial permeability transition by auranofin, a Gold(I)phosphine derivative. Br. J. Pharmacol. 2002, 136, 1162-1168. 